\title{
Influence of Ultrasonic Melt Treatment on Microstructure and Mechanical Properties of AlSi9Cu3 Alloy
}

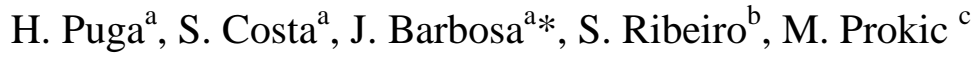 \\ ${ }^{\mathrm{a} C T 2 M}$ - Centre for Mechanical and Materials Technologies, Universidade do Minho, Azurém \\ 4800-058 Guimarães, Portugal
}

${ }^{\mathrm{b}}$ FEUP, Departamento de Eng ${ }^{\mathrm{a}}$ Metalúrgica e de Materiais, 4200-465 Porto, Portugal

${ }^{\mathrm{c}}$ MP Interconsulting, 2400 Le Locle, Switzerland

*Corresponding author. Tel: +351253510220/59; Fax: +351253516007

E-mail address: kim@dem.uminho.pt (J. Barbosa) 


\begin{abstract}
A novel MMM (Multi-frequency, Multimode, Modulated) ultrasonic (US) technology was used to refine the as cast microstructure and improve the mechanical properties of a AlSi9Cu3 alloy. Ultrasonic vibration was isothermally applied to the melt for 120 seconds at different temperatures slightly above the liquidus temperature of the alloy, using different electric power values, before pouring into a metallic mould. The microstructure of the cast samples was characterized by optical and scanning electron microscopy and energy dispersive spectrometry. Ultrasonic vibration promoted the formation of small $\alpha$-Al globular grains, changed the size and morphology of intermetallic compounds and distributed them uniformly throughout the castings. Ultimate Tensile Strength and Strain were increased to $332 \mathrm{MPa}$ and $2.9 \%$ respectively, which are $50 \%$ and $480 \%$ higher than the values obtained for castings produced without vibration. The microstructure morphology and the alloy mechanical properties were found to depend on the electric power and the melt temperature, and by using a suitable combination of these parameters it is possible to achieve high refinement efficiency by treating the melts in the liquid state.
\end{abstract}

Keywords: Aluminum alloys; Casting; Refinement; Ultrasound 


\section{Introduction}

\subsection{Microstructure of Al-Si based alloys}

Aluminum-silicon based alloys are the most widely used $\mathrm{Al}$ alloys for shape casting due to their high fluidity and castability, easy machinability and weldability, good corrosion resistance and mechanical properties. High mechanical strength is usually achieved by the addition of alloying elements such as Copper and Magnesium as they make the alloys heat treatable, although having a tendency to decrease ductility. Caceres et al. (2003) have shown that the strengthening effect of both alloying elements arises from the precipitation of $\mathrm{Cu}$-rich and $\mathrm{Mg}$-rich intermetallics during the traditional T6 age-hardening treatment, which have the ability to stop mobile dislocations, promoting strengthening. However, slowing down the mobility of dislocations reduces the alloys ductility, thus the elongation to fracture, which is still affected by the size, shape, morphology and volume fraction of $\mathrm{Al}_{2} \mathrm{Cu}, \mathrm{Mg}_{2} \mathrm{Si}$ and $\mathrm{Si}$ and Fe-rich intermetallics.

In the particular case of hypoeutectic AlSi9Cu3 alloy, besides a usually coarse and dendritic $\alpha$ Al solid solution and Al-Si eutectic, where Si usually assumes an acicular shape, Panuskova et al.(2008) and Backerud et al.(1990) reported the presence of intermetallic phases like the eutectic $\mathrm{Al}_{2} \mathrm{Cu}$, "Chinese script" shaped $\alpha-\mathrm{Al}_{15}(\mathrm{Mn}, \mathrm{Fe})_{3} \mathrm{Si}_{2}$ and long and sharp needles of $\beta$ $\mathrm{Al}_{5} \mathrm{FeSi}$, which precipitate in the interdendritic and intergranular regions, and are strongly detrimental to the alloy mechanical and fatigue properties. Li et al., 2004(a) have shown that Ultimate Tensile Strength, UTS, strongly decreases with increasing size and volume fraction of $\beta-\mathrm{Al}_{5} \mathrm{FeSi}$ platelets, due to their relatively low bond strength with the matrix. Moreover, combined with blocky $\mathrm{Al}_{2} \mathrm{Cu}$, they can reduce the alloy's ductility significantly. Due to their acicular morphology, they also act as crack initiation sites and combined with brittle eutectic silicon particles dramatically reduce the alloys impact strength, as demonstrated by Li et al, 2004(b). According to Ceschini et al.(2009), unmodified eutectic silicon particles with acicular morphology reduces elongation not only because they favor crack nucleation, but also crack 
propagation, since their continuous distribution in the alloy is an easy path for crack growth. Lados and Apelian (2004) reported that grain size has no significant influence on the fatigue crack growth response, since crack advance is controlled by microstructural features smaller than grain size, like porosity, secondary dendrite arm spacing (SDAS) and eutectic silicon particles. Controlling the microstructure of Al-Si based alloys is then of primary importance to achieve high mechanical performance, thus requiring suitable refinement and modification.

\subsection{Traditional microstructure refinement and modification techniques}

The grain size bears an inverse relationship to the number of solidification nuclei present in the liquid alloy that will act during solidification. Since each grain forms from one single nucleus, as great the number of nuclei, as more grains will form, thus their size will reduce. If the number of nuclei is sufficiently high, dendritic structures can be avoided as they will have no space to grow, and globular grains of primary $\alpha$-Al will preferentially form.

The traditional approach to increase nucleation is the chemical route, by adding master alloys, like Al-Ti or, preferentially, Al-Ti-B since the presence of Boron was found to enhance the grain refinement effect. Particles of $\mathrm{TiAl}_{3}, \mathrm{TiB}_{2}$ or $\mathrm{AlB}_{2}$ phases present on those alloys act as nuclei and are easilly enveloped by the $\alpha$-Al phase during cooling, promoting heterogeneous nucleation. The efficiency of the grain refiner strongly depends on the Al alloy composition, namely the Si content, which determines the most suitable Ti/B ratio in the master alloy and the minimum Titanium concentration in the melt, as reported by Sritharan and Li (1997), which is often difficult to control.

Besides grain refinement, García-Hinojosa et al. (2003) have shown that microstructure modification is crucial to improve the mechanical properties of $\mathrm{Al}-\mathrm{Si}-\mathrm{Cu}$ alloys, which is traditionally carried out by the addition of Al-Sr master alloys or Sodium based fluxes. Experiments with $\mathrm{AlSi} 7 \mathrm{Cu}$ revealed that Strontium modification changed the eutectic $\mathrm{Si}$ acicular-plates and $\mathrm{Al}_{2} \mathrm{Cu}$ blocks to fine eutectic colonies, improving the alloy mechanical 
properties, with particular emphasis to elongation to failure which increased 3 times. Nevertheless, Sr modification has a tendency to increase the alloys porosity (both density and pore size), as reported by Roy et al. (1996). Although porosity increase mechanism by $\mathrm{Sr}$ addition is not fully understood, Emadi et al. (1993) suggested that it can be explained by the decrease of the surface tension of the melt and the increase of the volumetric shrinkage. As a result, re-gassing of the melt is possible, increasing the amount of dissolved hydrogen, and shrinkage facilitates porosity formation, because the pores form in the early stage of solidification and can grow over a longer period of time, resulting in a larger pore size.

\subsection{Ultrasonic refinement and modification}

Besides the chemical technique, microstructure refinement can also be achieved by physical means, namely ultrasonic vibration. Khalifa et al. (2008) and Jian et al. (2005) demonstrated that it is possible to obtain non-dendritic and globular grains of primary $\alpha$-Al phase smaller than $100 \mu \mathrm{m}$ by supplying acoustic energy to molten AlSi7Mg, isothermally or during solidification, respectively. Ultrasonic vibration can also be used to refine hypereutectic Al-Si alloys, as demonstrated by Feng at al. (2008), who obtained equiaxed $\alpha$-Al crystals of around $40 \mu \mathrm{m}$ and homogeneously distributed primary Si phase with average size of $180 \mu \mathrm{m}$ in AlSi23 alloy.

Two models/mechanisms explaining the effect of ultrasonic vibration on grain refinement have been proposed by Eskin (1998): cavitation-enhanced heterogeneous nucleation and dendrite fragmentation. Cavitation-enhanced heterogeneous nucleation can be explained as follows: when a liquid metal is submitted to high intensity ultrasonic vibrations, the alternating pressure above the cavitation threshold brings about numerous tiny bubbles in the liquid metal, which start growing, pulsing on a continuous expansion/compression regime and finally collapse. During expansion, bubbles absorb energy in the melt, undercooling the liquid at the bubble-liquid interface, resulting in nucleation on the bubble surface. When bubbles collapse acoustic 
streaming develops in the melt, distributing the nuclei into the surrounding liquid producing a significant number of nuclei in the molten alloy, thus promoting heterogeneous nucleation. Dendrite fragmentation is explained using a different analysis: when cavitation develops, the shock waves generated by bubbles collapse lead to fragmentation of dendritic cells in the mushy zone, which are re-distributed throughout the melt by acoustic streaming, increasing the number of solidification nuclei. The main difference between both mechanisms, is that dendrite fragmentation only occurs in melts already containing a minimum solid fraction volume, while cavitation-enhanced heterogeneous nucleation can occur in melts with $100 \%$ liquid fraction volume. Although both mechanisms can occur, cavitation-enhanced heterogeneous nucleation seems to be considered the most valid hypothesis, as claimed by Jian et al. (2005), since globular/non-dendritic microstructures have not been obtained when the ultrasonic treatment occurred with the alloy in the mushy zone. This mechanism is also supported by Qian et al. (2009) who reported that no grain refinement occurred in zones of ultrasonically treated $\mathrm{Mg}$ based ingots adjacent to the cylindrical face of the sonotrode immersed in the melt, that correspond to those zones where a mushy state was firstly achieved. On the other hand, in the remaining zones of the ingots, grain refinement was clearly achieved as confirmed by a finest grain size. The purpose of this work is to study the effect of applying acoustic energy to the melt at different temperatures slightly above the liquidus temperature of the alloy on the microstructure and mechanical properties of AlSi9Cu3 alloy.

\section{Experimental}

\subsection{Aluminum alloy}

Table 1 shows the composition of the AlSi9Cu3 alloy used on this work, obtained by Optical Emission Spectrometry. 
Table 1 - Composition of the AlSi9Cu3 alloy used in this work

\begin{tabular}{lllllllll}
\hline Element & $\mathrm{Si}$ & $\mathrm{Fe}$ & $\mathrm{Mg}$ & $\mathrm{Cu}$ & $\mathrm{Mn}$ & $\mathrm{Zn}$ & $\mathrm{Sn}$ & $\mathrm{Al}$ \\
\hline $\mathrm{Wt} \%$ & 9.15 & 0.66 & 0.18 & 2.25 & 0.26 & 0.47 & 0.10 & $\mathrm{Bal}$. \\
\hline
\end{tabular}

Differential Scanning Calorimetry (DSC) was used to identify the main phase transformation temperatures and to select the temperatures for US processing (Figure 1). DSC was carried out between 20 and $700{ }^{\circ} \mathrm{C}$ on a TA Instruments - Model 2960SDT equipment, under argon atmosphere and using $10^{\circ} \mathrm{C} / \mathrm{min}$ cooling rate.

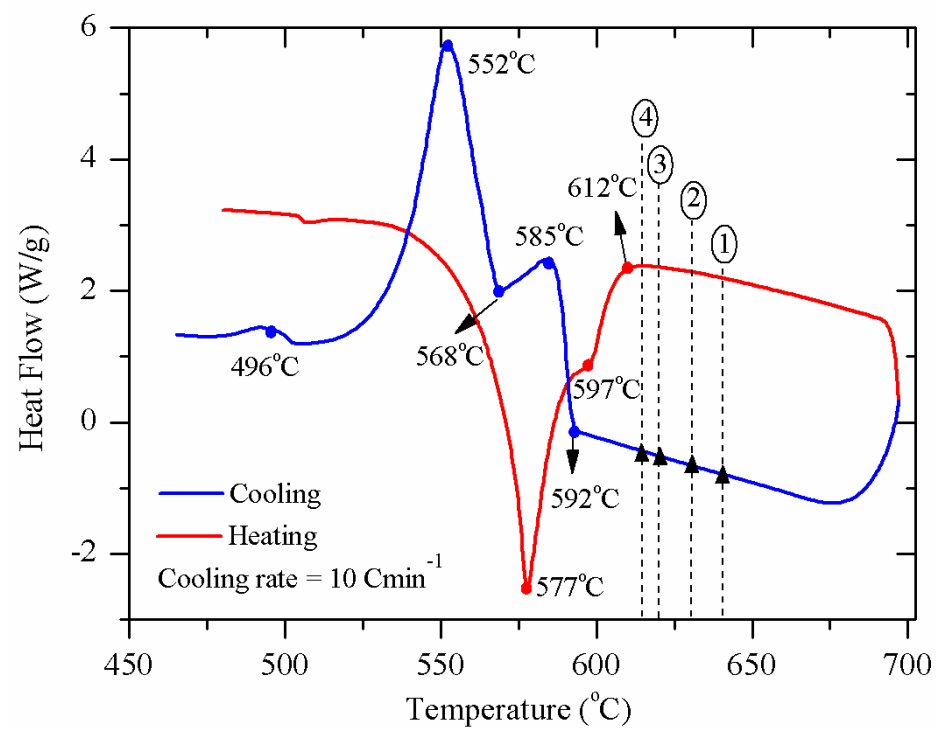

Figure 1 - DSC curves of AlSi9Cu3 alloy used in this work. Temperatures 1, 2, 3 and 4 were selected for US processing of the alloy, and correspond to $615,620,630$ and $640{ }^{\circ} \mathrm{C}$, respectively

\subsection{Experimental set-up for ultrasonic (US) refinement}

The experimental set-up (Figure 2) used in this work consisted of a novel MMM (Multifrequency, Multimode, Modulated technology) ultrasonic power supply unit developed by MP Interconsulting and protected by European Patent Application EP1238715, a high power ultrasonic converter $(1200 \mathrm{~W})$, a $30 \mathrm{~mm}$ diameter and $150 \mathrm{~mm}$ long acoustic waveguide and the acoustic load itself which consisted on a $12.5 \mathrm{~mm}$ diameter and $135 \mathrm{~mm}$ long Ti6Al4V acoustic radiator and the liquid metal. According to Prokic (2001) and Prokic (2011) MMM technology is characterized by synchronously exciting many vibration modes through the coupled harmonics 
and sub-harmonics in solids and liquid containers, by supplying different frequency and phase modulations to a carrier ultrasonic signal, which widens the resulting acoustic spectrum in liquids. This technology produces high intensity multimode, frequency and phase modulated vibrations that are continuous, uniform and repeatable, avoiding the creation of stationary and standing waves, so that the whole vibrating system (including the liquid media) is fully agitated, improving the refinement process.
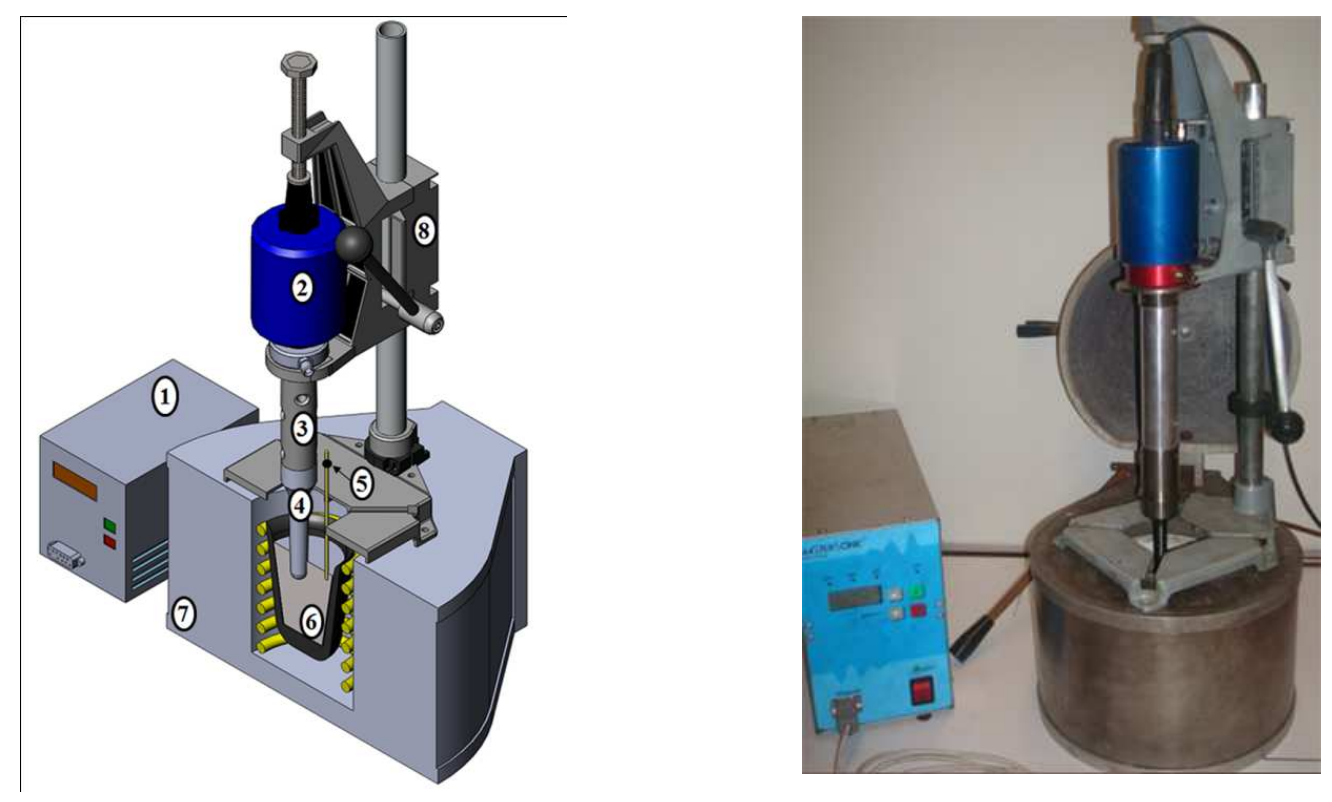

Figure 2 Experimental set-up: a) Conceptual model: 1- US supply unit, 2 - US converter, 3 Waveguide, 4 - Acoustic radiator, 5 - Thermocouple, 6 - Liquid alloy, 7 - Melting furnace, 8 Positioning device; b) Laboratorial unit

Standing waves in a liquid create zones of high and low acoustic activity, leading to spatially non-uniform liquid processing. MMM technology creates signal processing and oscillating conditions that are continuously moving and destroying possible standing waves, producing uniform, large band, "white noise cavitation activity". Results of such acoustic agitation are that liquid metal is uniformly sonicated and, consequently, refinement, degassing, wetting, alloying and homogenizing effects are significantly optimized and accelerated. The ultrasonic power supply unit is fully controlled by dedicated Windows compatible software developed by MPI. 
Optimal ultrasonic parameters related to frequency and phase modulation, such as frequency sweeping and repetition rate, and $f$ swm (frequency shift with modulation) for the selected resonance frequency and electric power are adjusted in order to produce the highest acoustic amplitude and the wide frequency spectrum in the melt, which is monitored with a specifically implemented feedback loop.

The set-up also includes a supporting and positioning device of the US unit and an electric furnace equipped with a 0.5 litre $\mathrm{SiC}$ crucible. The electrical waveform generated by the ultrasonic power supply unit (1) is converted in repetitive multi-frequency, phase-modulated mechanical vibrations by the ultrasonic converter (2), which are driven to the acoustic radiator (4) through the waveguide (3). The acoustic load (radiator and liquid) starts producing its own vibration, oscillating in one or more of its natural resonance frequencies.

\subsection{Melting and refinement procedure}

The alloy $(0.4 \mathrm{~kg})$ was melted and held inside the crucible at $700{ }^{\circ} \mathrm{C}$ during 15 minutes for homogenization, allowed to cool until the desired processing temperature and the acoustic radiator was deep $10 \mathrm{~mm}$ inside the melt. US vibration was applied isothermally for 120 seconds and the molten alloy poured into a steel die pre-heated at $300{ }^{\circ} \mathrm{C}$. For the sake of comparison experiments were also carried out without US vibration. Three experiments were carried out for each set of processing conditions. On each experiment, 2 cylindrical samples with $18 \mathrm{~mm}$ in diameter and $140 \mathrm{~mm}$ long were cast and used for mechanical testing and microstructure characterization.

According to DSC results, 615, 620, 630 and $640{ }^{\circ} \mathrm{C}$ melt temperatures were selected for US processing, corresponding to superheating of $3,8,18$ and $28{ }^{\circ} \mathrm{C}$, respectively. These temperatures were selected because they are slightly above liquidus temperature of the alloy, thus a localized slight undercooling induced by cavitation could easily promote nucleation. Melt temperature was controlled within an accuracy of $\pm 2{ }^{\circ} \mathrm{C}$. For every experiment, the acoustic 
radiator was heated at the same temperature of the isothermal processing, using a specially developed electrical heating device. Ultrasonic frequency of $19.8 \pm 0.25 \mathrm{kHz}$ at 200,400 and 600 $\mathrm{W}$ electric power were used for each processing temperature.

\subsection{Samples characterization}

Samples for microstructure characterization were taken from each cast sample by sectioning the cylinders perpendicularly to its longitudinal axis. They were ground by using $1200 \mathrm{SiC}$ paper, and polished up to $1 \mu \mathrm{m}$. Samples used for optical microscopy characterization were etched using Keller's reagent to reveal the resulting microstructure. Optical microscope with quantitative metallographic analysis capability was used to evaluate the shape and grain size of constituents. To evaluate $\alpha$-Al grain size, each grain was delimited by a contour line using Image Pro Plus Software, in order to determine its area. Average grain size was then calculated according to ASTM Standard E112-10. SDAS was measured as shown in Figure 3, in five $500 \times 400 \mu \mathrm{m}$ fields with $200 \times$ magnification. Phase identification and chemical composition were evaluated by quantitative EDS analysis using a high resolution FEI Quanta 400 FEG E Scanning Electron Microscope coupled to an EDAX Genesis X4M X-Ray Energy Dispersive Electron Spectrometer. The error associated to elements quantification was 0.2 at $\%$. $10 \mathrm{keV}$ potential and $100 \mathrm{~s}$ acquisition time were used for every evaluation. Traditional tensile test specimens with $100 \mathrm{~mm}$ length and test section of $\varnothing 8 \mathrm{~mm}$, according to EN10002-1(2006), were machined from the as-cast samples. Five specimens were tested for each processing condition, at room temperature and a strain rate of $0.5 \mathrm{~mm} / \mathrm{min}$ on a INSTRON machine - Model 8874, to obtain yield strength, ultimate tensile strength and strain.

\section{Results and discussion}

\subsection{Microstructure of as-cast AlSi9Cu3 without US treatment}

The microstructure of as-cast AlSi9Cu3 was fully dendritic, with some branch length of $700 \mu \mathrm{m}$, as shown in Figure 3. Average SDAS was $45 \mu \mathrm{m}$, calculated according to the procedure referred 
in Section 2.4. Coarse acicular eutectic silicon about $60 \mu \mathrm{m}$ long and average area around $120 \mu \mathrm{m}^{2}$ was also present in the interdendritic areas. Besides $\alpha$-Al and Si plates, SEM analysis revealed different heterogeneously distributed intermetallic phases, as presented in Figure 4, which morphology and chemical analysis (Table 2) suggest to be "Chinese script" shaped $\alpha$ $\mathrm{Al}_{15}(\mathrm{Mn}, \mathrm{Fe})_{3} \mathrm{Si}_{2}(\mathrm{Z1})$, eutectic $\mathrm{Al}_{2} \mathrm{Cu}(\mathrm{Z2})$ and long needles of $\beta$ - $\mathrm{Al}_{5} \mathrm{FeSi}$ (Z3), confirming reports of Panuskova et al. (2008) and Backerud et al. (1990) who have found the same intermetallic compounds in similar alloys. The long needles of $\beta-\mathrm{Al}_{5} \mathrm{FeSi}$ (light grey needles in Figure 4) were, in some cases, more than $200 \mu \mathrm{m}$ long. Besides its highly detrimental effect in the alloy mechanical properties, this morphology can promote shrinkage porosity since the platelets restrict feeding by causing physical restrictions to the movement of compensatory feeding liquid, as reported by Panuskova et al. (2008) and Roy et al. (1996).

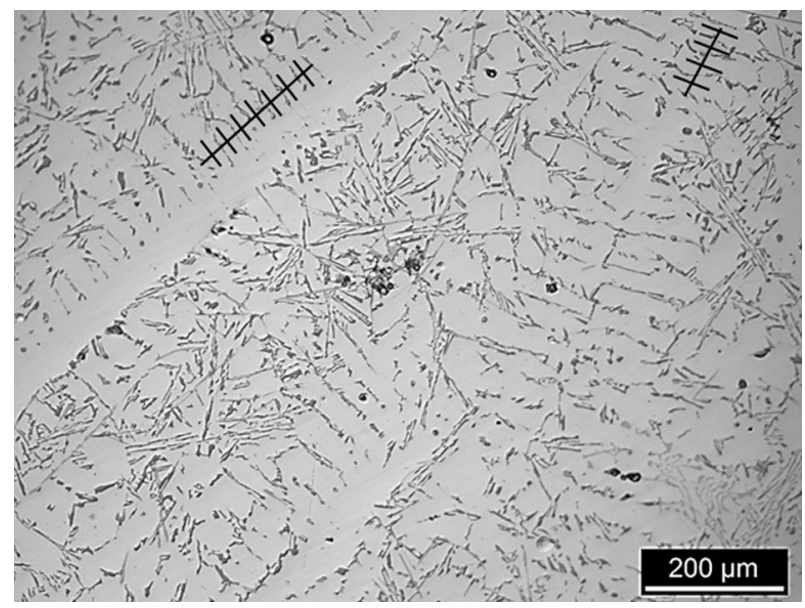

Figure 3 - Microstructure of as-cast AlSi9Cu3 without US processing, revealing long dendrites and showing how average SDAS was measured

Table 2 - Chemical composition of intermetallic phases detected on the as-cast AlSi9Cu3 alloy produced without treatment with acoustic energy, corresponding to phases Z1, Z2 and Z3 indicated in Figure 4

\begin{tabular}{|c|c|c|c|c|c|}
\hline \multirow{2}{*}{ Constituent } & \multicolumn{5}{|c|}{ Composition (at \%) } \\
\cline { 2 - 6 } & $\mathrm{Al}$ & $\mathrm{Si}$ & $\mathrm{Fe}$ & $\mathrm{Cu}$ & $\mathrm{Mn}$ \\
\hline $\mathrm{Z} 1$ & 65.0 & 11.0 & 14.1 & 1.2 & 8.7 \\
\hline $\mathrm{Z} 2$ & 52.2 & - & - & 47.8 & - \\
\hline $\mathrm{Z3}$ & 70.2 & 13.4 & 16.4 & - & - \\
\hline
\end{tabular}




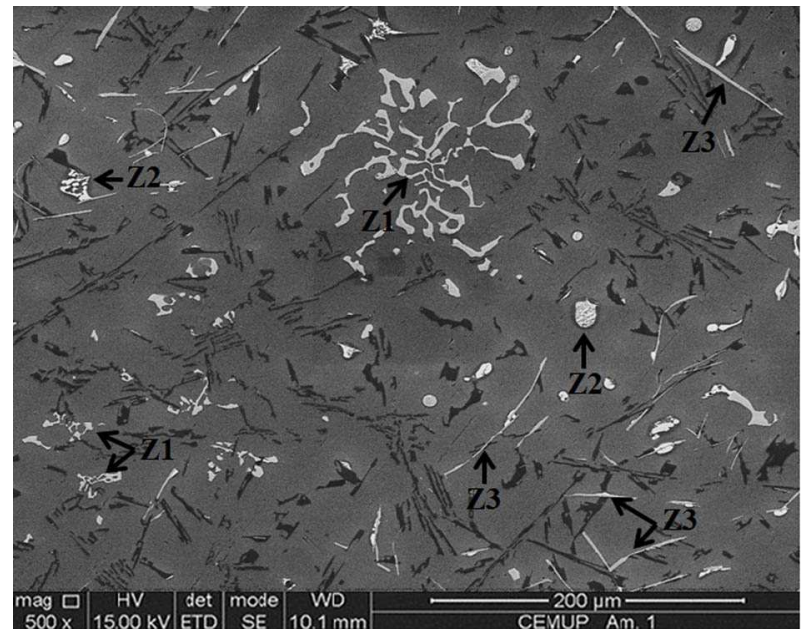

Figure 4 - SEM image of the AlSi9Cu3 alloy without treatment with acoustic energy, revealing the presence of well developed and coarse: $\mathrm{Z1}-\alpha-\mathrm{Al}_{15}(\mathrm{Fe}, \mathrm{Mn})_{3} \mathrm{Si}_{2} ; \mathrm{Z} 2-\mathrm{Al}_{2} \mathrm{Cu} ; \mathrm{Z} 3-\beta-\mathrm{Al}_{5} \mathrm{FeSi}$ intermetallic phases

\subsection{Microstructure of as-cast AlSi9Cu3 submitted to US treatment}

Figure 5 presents the as-cast microstructure of the AlSi9Cu3 alloy isothermally submitted to acoustic energy in the range of $615-640^{\circ} \mathrm{C}$, at $400 \mathrm{~W}$ electric power and $19.8 \mathrm{kHz}$ frequency.

At $640{ }^{\circ} \mathrm{C}$, the US treatment promoted the formation of coarse rosette like $\alpha$-Al grains with average size around $65 \mu \mathrm{m}$. For temperatures of 630 and $620^{\circ} \mathrm{C}$ the alloy microstructure was a mix of small rosette like and globular $\alpha$-Al grains, with average size around $55 \mu \mathrm{m}$. At $615^{\circ} \mathrm{C}$, the effect over the solidification microstructure was much higher, leading to dominant fine nonedendritic and globular grains with average grain size around $43 \mu \mathrm{m}$. Besides grain refinement, size, thickness, size and spacing between eutectic silicon lamellae decreased (Figure 6), and that effect increased with decreasing processing temperature. However, the effect of US on eutectic silicon modification was not a major objective of this work and further research on this specific field is necessary to evaluate the US treatment capability on eutectic silicon modification.

The effect of temperature on the efficiency of grain refinement can be explained as follows: Firstly, as every experiment was performed above the liquidus temperature of the alloy, grain refinement and absence of dendritic shaped cells in the microstructure can only be attributed to 
cavitation-enhanced heterogeneous nucleation, since dendrite fragmentation would not be possible at those temperatures since solidification had not started yet. Secondly, different grain refinement efficiency at different temperatures can be explained by the survival time of the acoustically induced nuclei. In fact, Eskin (1998) refer that the developed nuclei is highly thermodynamically unstable since they form at the interfaces between the cavitation bubbles and the melt during the expansion stage of the bubbles and dissolve in the melt when bubbles collapse. As higher the melt temperature as shorter the survival time of those nuclei, thus decreasing the quantity of embryos in the melt and the number of globular grains in the final microstructure. As a consequence of such instability, it was possible the co-existence of both dendritic and globular grains, as it happened for melt treatment temperatures of 620 and $630{ }^{\circ} \mathrm{C}$. At $640{ }^{\circ} \mathrm{C}$, the number of active nuclei in the melt was quite low, as well as their thermal stability, resulting in higher grain sizes and rosette like structures. At $615^{\circ} \mathrm{C}$ the embryos life time was long enough to promote a high density of nuclei in the melt, thus leading to the development of a large number of globular grains with small grain size. Moreover, as referred in Section 1.3, acoustic streaming also contributed to disseminate solidification nuclei throughout the melt, thus increasing the grain refinement efficiency. According to Eskin (1998), when the propagation media is a liquid metal, the liquid viscosity is a major variable in the development of streams, since it directly affects sound absorption. This means that acoustic streams were stronger for lower temperatures and potentiated the grain refinement efficiency of US treatment at $615^{\circ} \mathrm{C}$.

Besides temperature, electric power also played an important role on microstructure refinement, as shown in Figure 7. For each processing temperature increasing electric power promoted higher grain refinement. However, the decrease in grain size with increasing power was not linear since it became less effective after reaching a certain power level (400 and $600 \mathrm{~W}$ curves are much closer than 200 and $400 \mathrm{~W}$ curves). 

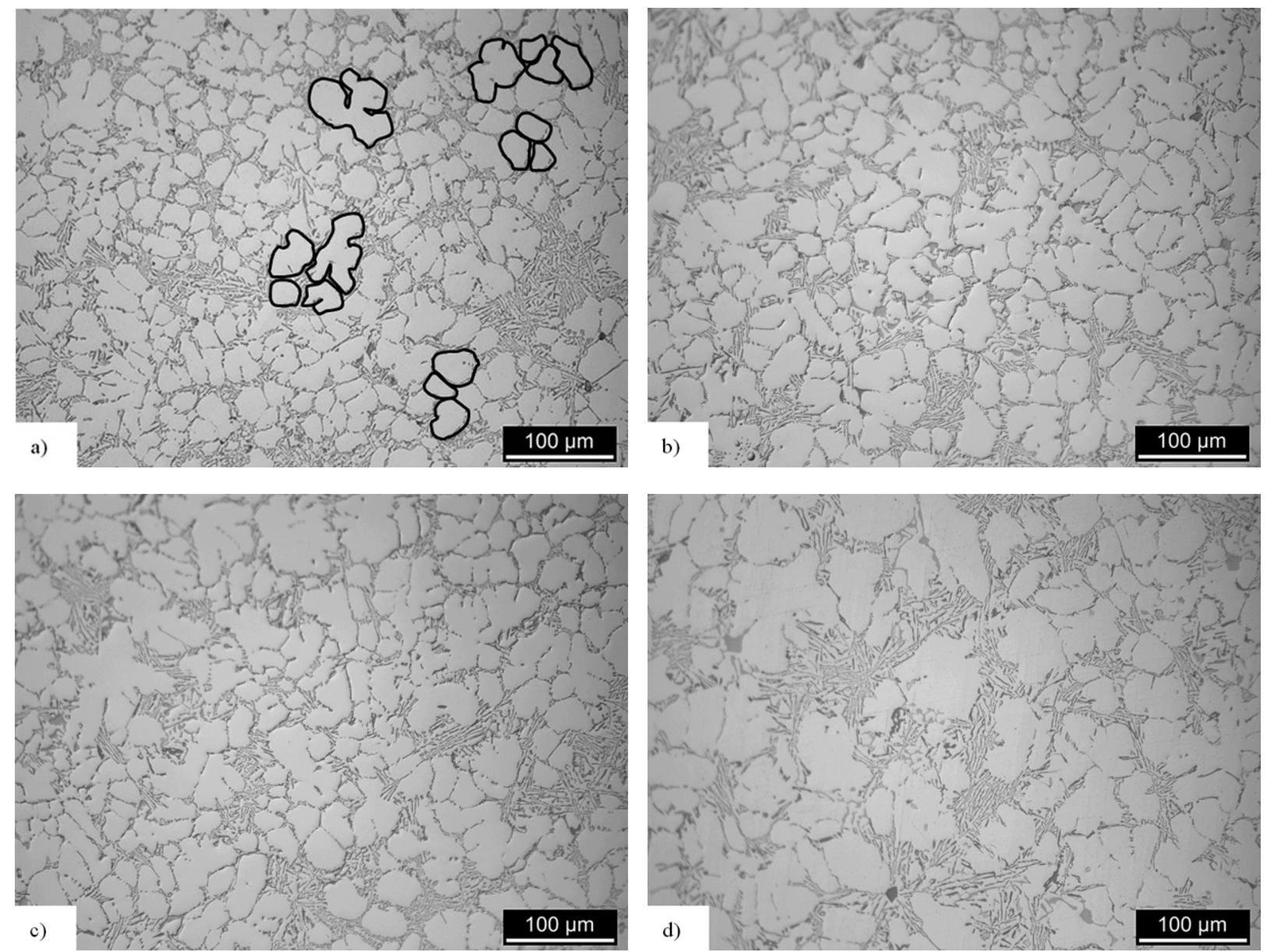

Figure 5 - Microstructure of AlSi9Cu3 alloy US treated at a) $615^{\circ} \mathrm{C}$; b) $620^{\circ} \mathrm{C}$; c) $630{ }^{\circ} \mathrm{C}$ and d) $640{ }^{\circ} \mathrm{C}$ during 120 seconds, at $400 \mathrm{~W}$ electric power and $19.8 \mathrm{kHz}$ frequency. Fig 5a) shows how $a$-Al grains were delimited in order to measure its area and average size.
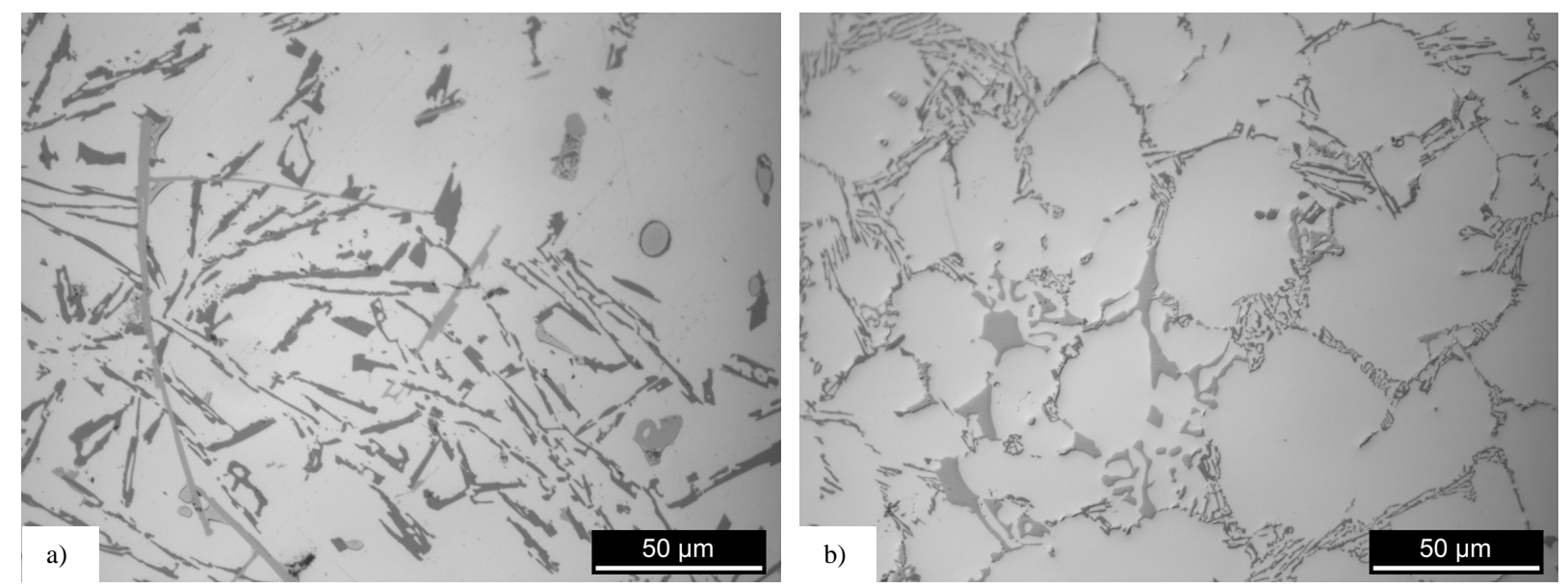

Figure 6 - Eutectic silicon morphology of a AlSi9Cu3: a) non-Us treated and b) US treated at $400 \mathrm{~W}$ and $615^{\circ} \mathrm{C}$ melt temperature 
For $615{ }^{\circ} \mathrm{C}$, for example, a power increase from 200 to $400 \mathrm{~W}$ led to a decrease in grain size from 61 to $43 \mu \mathrm{m}$. However, when power was increased to $600 \mathrm{~W}$, the grain size decreased only to $41 \mu \mathrm{m}$. The effect of electric power in the final grain size is a consequence of the cavitation intensity and the number of cavitation bubbles induced at each power level. As higher the electric power as higher the number of cavitation bubbles that develop in the melt, thus the higher number of solidification nuclei and the smaller final grain size in the solidified alloy. Moreover, Eskin (1998) and Abramov (1998) referred that the intensity of acoustic streams that develop during cavitation and promote the distribution of nuclei throughout the melt depends on the electric power and the sound absorption. Thus, besides generating high cavitation intensity, high electric power also promoted strong acoustic streaming and the combined effect of these two factors strongly increased the efficiency of US grain refinement.

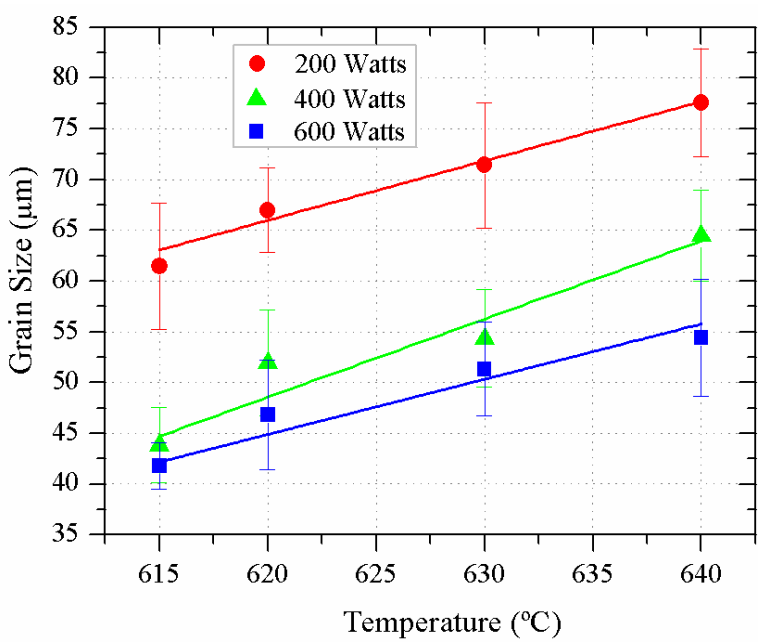

Figure $7-\alpha$-Al grain size of AlSi9Cu3 alloy as a function of US treatment temperature, for different electric power levels and US frequency of $19.8 \mathrm{kHz}$

The chemical composition of the intermetallic phases detected in both US-treated (Table 3) and non treated $\mathrm{AlSi} 9 \mathrm{Cu} 3$ suggest that they were the same, however they were better distributed and reveal a different morphology in the US-treated samples (Figure 8), which is agreement with reports of Khalifa et al. (2010). The coarse "Chinese script" $\alpha-\mathrm{Al}_{15}(\mathrm{Fe}, \mathrm{Mn})_{3} \mathrm{Si}_{2}$ phase was replaced by thin particles with different shapes, which length (average value around $30 \mu \mathrm{m}$ ) was 
much shorter than in the non US-treated alloy, and was better distributed throughout the matrix. The area of the $\mathrm{Al}_{2} \mathrm{Cu}$ phase was also reduced although its morphology didn't suffer significant change. The major change was verified for the $\beta-\mathrm{Al}_{5} \mathrm{FeSi}$ phase, since its average length decreased from around $81 \mu \mathrm{m}$ to around $10 \mu \mathrm{m}$ (Figure 9) and those needles more $200 \mu \mathrm{m}$ long were not found, since they this phase was fully refined and homogeneously distributed as small particles throughout the samples. The average $\alpha-\mathrm{Al}$ grain size and the $\beta-\mathrm{Al}_{5} \mathrm{FeSi}$ length decreased to $41 \mu \mathrm{m}$ and $6 \mu \mathrm{m}$, respectively, for $600 \mathrm{~W}$, although higher refinement can hardly be expected for higher power values.

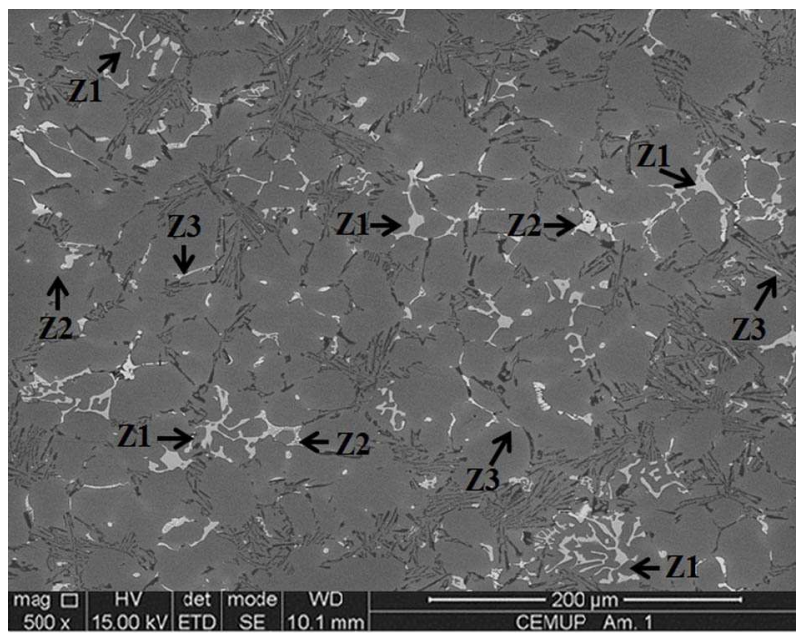

Figure 8 - SEM image of the AlSi9Cu3 alloy with US treatment at $400 \mathrm{~W}$ and $615^{\circ} \mathrm{C}: \mathrm{Z} 1-\alpha-$ $\mathrm{Al}_{15}(\mathrm{Fe}, \mathrm{Mn})_{3} \mathrm{Si}_{2} ; \mathrm{Z} 2-\mathrm{Al}_{2} \mathrm{Cu} ; \mathrm{Z} 3-\beta-\mathrm{Al}_{5} \mathrm{FeSi}$ intermetallic phases

Table 3 - Chemical composition of intermetallic phases detected on the as-cast AlSi9Cu3 alloy with US treatment, corresponding to phases Z1, Z2 and Z3 of Figure 8

\begin{tabular}{|c|c|c|c|c|c|}
\hline \multirow{2}{*}{ Constituent } & \multicolumn{5}{|c|}{ Composition (at\%) } \\
\cline { 2 - 6 } & $\mathrm{Al}$ & $\mathrm{Si}$ & $\mathrm{Fe}$ & $\mathrm{Cu}$ & $\mathrm{Mn}$ \\
\hline $\mathrm{Z} 1$ & 63.8 & 12.2 & 14.0 & 1.4 & 8.6 \\
\hline $\mathrm{Z} 2$ & 56.3 & - & - & 43.7 & - \\
\hline $\mathrm{Z} 3$ & 69.4 & 16.1 & 14.5 & - & - \\
\hline
\end{tabular}

The US refinement mechanism of intermetallic compounds on $\mathrm{Al}-\mathrm{Si}-\mathrm{Cu}$ alloys is not well understood, and available references on this field are very scarce, requiring more research work on this particular field. According to Backerud et al. (1990), for this particular alloy the crystallization temperatures of $\mathrm{CuAl}_{2}, \alpha-\mathrm{Al}_{15}(\mathrm{Fe}, \mathrm{Mn})_{3} \mathrm{Si}_{2}$ and $\beta$-Al5FeSi are located in the intervals $\left(492-509^{\circ} \mathrm{C}\right),(560-566)$ and $(570-582)$, respectively, which are well below the 
treatment temperatures. This suggests that their modification was not due to the US vibration itself, but it is a consequence of other factors promoted by the US vibration. A possible explanation might be the decrease of the intergranular spacing due to the formation of a large number of globular $\alpha$-Al grains, which might have restricted the growth of intermetallic phases, particularly the $\beta$ - $\mathrm{Al}_{5} \mathrm{FeSi}$ compound. For the same reason, and as the $\beta-\mathrm{Al}_{5} \mathrm{FeSi}$ phase forms directly from the liquid after the primary $\alpha$-Al grains, the volume of reminiscent liquid at the formation temperature of $\beta-\mathrm{Al}_{5} \mathrm{FeSi}$ is also less, reducing the phase size.

\subsection{Mechanical properties}

In those samples without US treatment average UTS was $220 \mathrm{MPa}$, which increased to 266, 296 and $332 \mathrm{MPa}$ after US processing at 200, 400 and $600 \mathrm{~W}$ electric power and $615^{\circ} \mathrm{C}$ melt temperature, respectively. Besides UTS, Strain increased from $0.6 \%$ to $0.9,1.6$ and $2.9 \%$ after processing at 200,400 and $600 \mathrm{~W}$, respectively, for $615^{\circ} \mathrm{C}$ treatment temperature (Fig. 10).

It is well known that mechanical properties of Al-Si alloys depend on several factors, as referred in Section 1.1. Panuskova et al. (2008) demonstrated that the morphology and distribution of eutectic silicon have the most significant influence on the change in the mechanical properties, although the size and morphology of the primary aluminum phase, as well as porosity distribution, can also play a significant role in the alloy mechanical behavior. Moreover, in the particular case of $\mathrm{Al}-\mathrm{Si}-\mathrm{Cu}$ alloys, the sharp ends of the brittle $\beta-\mathrm{Al}_{5} \mathrm{FeSi}$ acicular phase can act as stress concentrators, decreasing the alloy ductility, as referred by Gao et al. (2004). Taking into consideration these principles, UTS increase can be attributed to the combined effect of the globular shape and size of the $\alpha$ - $\mathrm{Al}$ grain, the size reduction of the $\beta-\mathrm{Al}_{5} \mathrm{FeSi}$ phase and the fine and short eutectic silicon fibers. Although porosity and inclusions have not been characterized, US processed alloys didn't evidence significant presence of pores or inclusions (Figure 5) in opposition to the microstructure of non-US processed alloys (Figure 3). However, its contribution to the UTS increase can't be excluded. Figure 9 shows that for power values above $400 \mathrm{~W}$ the reduction of $\alpha$-Al grain size and $\beta$ - $\mathrm{Al}_{5} \mathrm{FeSi}$ length tends to stabilize, but UTS continues to increase linearly at the same rate, suggesting that other factors must be taken into consideration to explain such behavior. From Figure 10 it is clear that the average area of eutectic silicon fibers decrease exponentially with increasing electric power, even for power values above $400 \mathrm{~W}$. These results suggest that UTS increase was more sensitive to the eutectic 
morphology then to the refinement of $\alpha-\mathrm{Al}$ and $\beta-\mathrm{Al}_{5} \mathrm{FeSi}$ phases, and may explain its linear increase above $400 \mathrm{~W}$.

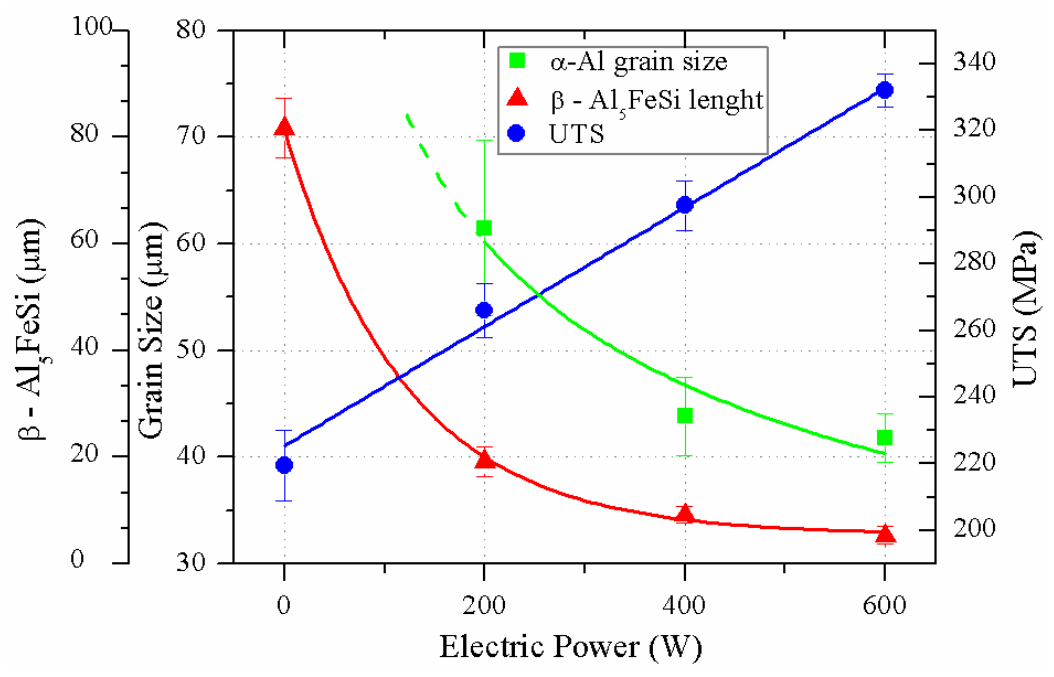

Figure 9 - $\alpha$-Al grain size, $\beta$ - $\mathrm{Al}_{5} \mathrm{FeSi}$ needles length and UTS of AlSi9Cu3 samples US treated at $19.8 \mathrm{kHz}$ and $615^{\circ} \mathrm{C}$, for different electric power values

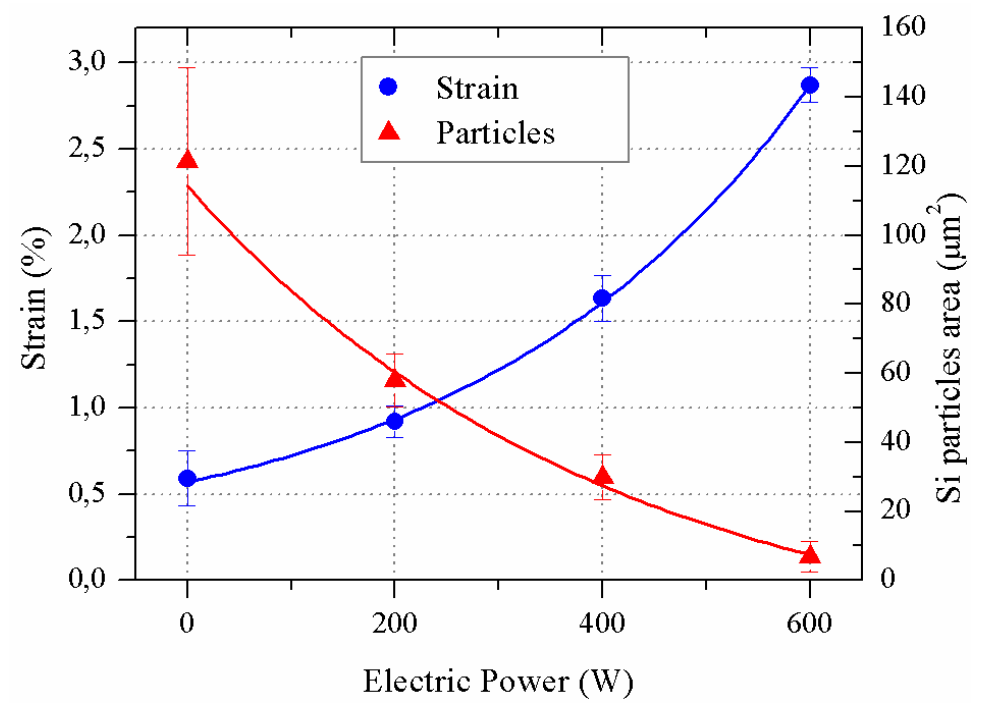

Figure 10 - Average area of eutectic silicon particles and Strain of AlSi9Cu3 samples US treated at $19.8 \mathrm{kHz}$ and $615^{\circ} \mathrm{C}$, for different electric power values

In what concerns to elongation to failure (it increased exponentially with the electric power in the range 200 to $600 \mathrm{~W}$ ), Figure 10 suggests a direct relationship with the average area of eutectic silicon particles, which decreased exponentially within the same electric power range. However, modification of the morphology and homogeneous distribution of the $\beta$ - $\mathrm{Al}_{5} \mathrm{FeSi}$ phase may have also contributed to increase the alloy ductility. 


\section{Conclusions}

A study was carried out to evaluate the influence of ultrasonic melt treatment in the microstructure and mechanical properties of AlSi9Cu3 alloy. The effect of treatment temperature and electric power was studied and, for the processing conditions used on this work, the results showed that:

- Ultrasonic treatment is an efficient physical technique to control the morphology and size of primary aluminum grains, refinement and distribution of intermetallic phases and promotes eutectic silicon modification;

- US melt treatment promotes the formation of globular grains of $\alpha$-Al, which size depends on the melt temperature and electric power. Globular $\alpha$-Al grain sizes with $41 \mu \mathrm{m}$ were obtained for $615^{\circ} \mathrm{C}$ and $600 \mathrm{~W}$. Higher temperatures and lower power values didn't avoid the development of some rosette like grains and showed lower grain refinement efficiency;

- For $615^{\circ} \mathrm{C}$ the iron containing intermetallic phases changed their morphology from large needles or coarse "Chinese Script" shape into short and thin particles with different shapes, uniformly distributed throughout the matrix. The intermetallics size decreased exponentially with increasing electric power until $600 \mathrm{~W}$, and no further decrease is expected for higher power values;

- The morphology of eutectic silicon was modified from a coarse acicular plate like shape in samples without US-treatment into a fibrous like shape with average area of $10 \mu \mathrm{m}^{2}$, for $615^{\circ} \mathrm{C}$ and $600 \mathrm{~W} ;$

- Microstructure modification was followed by an increase in mechanical properties and the best results were obtained for $615^{\circ} \mathrm{C}$ and $600 \mathrm{~W}$. For these processing conditions, and when compared with non US-treated alloys, UTS increased from 220 to $332 \mathrm{MPa}$ and Strain from $0.6 \%$ to $2.9 \%$, respectively.

Although some of the ultrasonic melt treatment benefits in Al-Si based alloys are already quite well understood, the mechanisms inherent to some phenomena like eutectic silicon and intermetallic phases modification are not clear and further research is necessary to understand them. 


\section{References}

Abramov, O.V., 1998. High-Intensity Ultrasonics Theory and Industrial Applications, first edition. Gordon and Breach Science Publishers, Amsterdam.

Backerud, L., Chai, G., Tamminen, J., 1990. Solidification Characteristics of Aluminum Alloys. Vol. 2: Foundry Alloys. AFS/Skanaluminium, Stokholm.

Caceres, C.H., Svensson, I.L., Taylor, J.A., 2003. Strength-ductility behaviour of Al-Si-Cu-Mg casting alloys in T6 temper. International Journal of Cast Metals Research 15, 531-543.

Ceschini, L., Boromei, I., Morri, A., Seifeddine, S., Svensson, I., 2009. Microstructure, tensile and fatigue properties of the $\mathrm{Al}-10 \% \mathrm{Si}-2 \% \mathrm{Cu}$ alloy with different $\mathrm{Fe}$ and $\mathrm{Mn}$ content cast under controlled conditions. Journal of Materials Processing Technology 209, 5669-5679.

Emadi, D., Gruzleski, J.E., Toguri, J.M., 1993. The effect of Na and Sr modification on surface tension and volumetric shrinkage of A356 alloy and their influence on porosity formation. Metallurgical Transactions B 24B, 1055-1063.

Eskin, G.I., 1998. Ultrasonic Treatment of Light Alloy Melts, first edition. Gordon and Breach Science Publishers, Amsterdam.

Feng, H.K., Yu, S.R., Li, Y.L., Gong, L.Y., 2008. Effect of ultrasonic treatment on microstructures of hypereutectic Al-Si alloy. Journal of Materials Processing Technology 208, 330-335.

Gao, Y.X., Yi, J.Z., Lee, P.D., Lindley, T.C., 2004. A micro-cell model of the effect of microstructure and defects on fatigue resistance in cast aluminum alloys. Acta Materialia 52 (19) 5435-5449.

García-Hinojosa, J.A., González, C.R., González, G.M., Houbaert, Y., 2003. Structure and properties of Al-7Si-Ni and Al-7Si-Cu cast alloys nonmodified and modified with Sr. Journal of Materials Processing Technology 143-144, 306-310. 
Jian, X., Xu, H., Meek, T.T., Han, Q., 2005. Effect of power ultrasound on solidification of aluminum A356 alloy. Materials Letters 59, 190-193.

Khalifa, W., Tsunekawa, Y., Okumiya, M., 2008. Effect of ultrasonic melt treatment on microstructure of A356 aluminium cast alloys. International Journal of Cast Metals Research 21, 129-134.

Khalifa, W., Tsunekawa, Y., Okumiya, M., 2010. Effect of Ultrasonic Melt-Treatment on the Eutectic Silicon and Iron Intermetallic Phases in Al-Si cast Alloys. Materials Science Forum 638-642, 431-436.

Lados, D.A., Apelian, D., 2004. Fatigue crack growth characteristics in cast Al-Si-Mg alloys Part I. Effect of processing conditions and microstructure. Materials Science and Engineering A $385,200-211$.

Li, Z., Samuel, A.M., Samuel, F.H., Ravindran, C., Valtierra, S., Doty, H.W., 2004 (a). Parameters controlling the performance of AA319-type alloys: Part I. Tensile properties. Materials Science and Engineering A 367, 96-110.

Li, Z., Samuel, A.M., Samuel, F.H., Ravindran, C., Doty, H.W., Valtierra, S., 2004 (b).

Panuskova, M., Tillova, E., Chalupova, M., 2008. Relation between Mechanical Properties and Microstructure of Cast Aluminum Alloy AlSi9Cu3. Strength of Materials 40, 98-101.

Prokic, M., 2001. European Patent Application EP1238715.

Prokic, M., 2011. Wideband Multi-frequency, Multimode, and Modulated (MMM) Ultrasonic Technology. In Feng, H., Barbosa-Casanovas, G., Weiss, J. (Eds), Ultrasound Technologies for Food and Bioprocessing. Springer Science + Business Media, New York, pp. 125-140.

Qian, M., Ramirez, A., Das, A., 2009. Ultrasonic refinement of magnesium by cavitation: Clarifying the role of wall crystals. Journal of Crystal Growth 311, 3708-3715. 
Roy, N., Samuel, A.M., Samuel, F.H., 1996. Porosity formation in Al-9 wt pet Si-3 wt pct Cu alloy systems: Metallographic observations. Metallurgical and Materials Transactions A 27, 415429.

Sritharan, T., Li, H., 1997. Influence of titanium to boron ratio on the ability to grain refine aluminium-silicon alloys. Journal of Materials Processing Technology 63, 585-589. 


\section{Figure Captions}

Figure 1 - DSC curves of AlSi9Cu3 alloy used in this work. Temperatures 1, 2, 3 and 4 were select for ultrasonic processing of the alloy, and correspond to $615,620,630$ and $640{ }^{\circ} \mathrm{C}$, respectively

Figure 2 Experimental set-up: a) Conceptual model: 1- US supply unit, 2 - US converter, 3 Waveguide, 4 - Acoustic radiator, 5 - Thermocouple, 6 - Liquid alloy, 7 - Melting furnace, 8 Positioning device; b) Laboratorial unit

Figure 3 - Microstructure of as-cast AlSi9Cu3 without US processing, revealing long dendrites and showing how average SDAS was measured

Figure 4 - SEM image of the AlSi9Cu3 alloy without treatment with acoustic energy, revealing the presence of well developed and coarse: $\mathrm{Z1}-\alpha-\mathrm{Al}_{15}(\mathrm{Fe}, \mathrm{Mn})_{3} \mathrm{Si}_{2} ; \mathrm{Z} 2-\mathrm{Al}_{2} \mathrm{Cu} ; \mathrm{Z3}-\beta-\mathrm{Al}_{5} \mathrm{FeSi}$ intermetallic phases

Figure 5 - Microstructure of AlSi9Cu3 alloy US treated at a) $615^{\circ} \mathrm{C}$; b) $620^{\circ} \mathrm{C}$; c) $630{ }^{\circ} \mathrm{C}$ and d) $640{ }^{\circ} \mathrm{C}$ during 120 seconds, at $400 \mathrm{~W}$ electric power and $19.8 \mathrm{kHz}$ frequency. Fig 5a) shows how $a-\mathrm{Al}$ grains were delimited in order to measure its area and average size.

Figure 6 - Eutectic silicon morphology of a AlSi9Cu3: a) non-Us treated and b) US treated at $400 \mathrm{~W}$ and $615^{\circ} \mathrm{C}$ melt temperature

Figure $7-\alpha$-Al grain size of $\mathrm{AlSi} 9 \mathrm{Cu} 3$ alloy as a function of US treatment temperature, for different electric power levels and US frequency of $19.8 \mathrm{kHz}$

Figure 8 - SEM image of the AlSi9Cu3 alloy with US treatment at $400 \mathrm{~W}$ and $615^{\circ} \mathrm{C}: \mathrm{Z} 1-\alpha$ $\mathrm{Al}_{15}(\mathrm{Fe}, \mathrm{Mn})_{3} \mathrm{Si}_{2} ; \mathrm{Z} 2-\mathrm{Al}_{2} \mathrm{Cu} ; \mathrm{Z} 3-\beta-\mathrm{Al}_{5} \mathrm{FeSi}$ intermetallic phases

Figure 9 - $\alpha$-Al grain size, $\beta$ - $\mathrm{Al}_{5} \mathrm{FeSi}$ needles length and UTS of AlSi9Cu3 samples US treated at $19.8 \mathrm{kHz}$ and $615^{\circ} \mathrm{C}$, for different electric power values

Figure 10 - Average area of eutectic silicon particles and Strain of AlSi9Cu3 samples US treated at $19.8 \mathrm{kHz}$ and $615^{\circ} \mathrm{C}$, for different electric power values 


\section{Table Captions}

Table 1 - Composition of the AlSi9Cu3 alloy used in this work

Table 2 - Chemical composition of intermetallic phases detected on the as-cast A1Si9Cu3 alloy produced without treatment with acoustic energy, corresponding to phases $\mathrm{Z} 1, \mathrm{Z} 2$ and $\mathrm{Z} 3$ indicated in Figure 4

Table 3 - Chemical composition of intermetallic phases detected on the as-cast AlSi9Cu3 alloy with US treatment, corresponding to phases Z1, Z2 and Z3 of Figure 8 